\title{
Uso discricionário das receitas de petróleo no Brasil: dinâmicas federativas
}

\author{
BENI TROJBICZ ${ }^{1}$ \\ CATARINA IANNI SEgATtO ${ }^{2}$ \\ ${ }^{1}$ UNIVERSIDAde FEDERAL dos VALES Do JeQUITINHONHA E MUCURI / FACULDADE INTERDISCIPLINAR DE HUMANIDADES, DIAMANTINA - MG, BRASIL \\ 2 Universidade Federal do ABC / Centro de Engenharia, Modelagem e CiÊncias Sociais Aplicadas, SÃo Bernardo do CAMPo - SP, Brasil
}

\section{Resumo}

Este artigo analisa o caso brasileiro de centralização federal das receitas do petróleo, para mostrar como as preferências das jurisdições podem direcionar a dinâmica federal por meio de mecanismos federativos do centro. O estudo trabalha abordagens históricas e institucionais que explicam continuidade e mudança nos regimes territoriais. Especificamente, analisamos a perda de poder discricionário no uso de recursos petrolíferos por meio da avaliação de se e como essas mudanças afetaram a aprovação da Lei Nacional 12.858 em 2013, que determinou que o governo federal, estados e municípios devem gastar sua parcela das receitas do petróleo em educação e saúde. Mostramos a forma como as preferências subnacionais afetam as políticas federais, destacando a importância da causalidade e do contexto, institucional e político, indicando um retorno a um padrão de governabilidade que parecia estar enterrado com o plano de estabilização econômica em 1994.

Palavras-chave: Federalismo. Receitas petrolíferas. Brasil.

\section{The discretionary use of oil revenues in Brazil: Federal dynamics}

\begin{abstract}
This article analyzes the Brazilian case of federal centralization of oil revenues, to show how jurisdictions' preferences may direct federal dynamics through central federative mechanisms. The study uses historical and institutional approaches that explain continuity and change in territorial regimes. Specifically, we analyse the loss of discretionary power in the use of oil resources through the understanding whether and how these changes affected the approval of National Law 12858 in 2013, which determined that federal government, states, and municipalities should spend their share of oil revenues on education and health. We show the way subnational preferences affect federal policies, highlighting the importance of causality and context, both politically and institutionally, and indicating a return to a governability pattern that seemed to be buried with the economic stabilization plan of 1994.
\end{abstract}

Keywords: Federalism. Oil revenues. Brazil.

\section{Uso discrecional de los ingresos petroleros en Brasil: dinámica federativa}

\section{Resumen}

Este artículo analiza el caso brasileño de centralización federal de los ingresos petroleros, para mostrar cómo las preferencias de las jurisdicciones pueden dirigir la dinámica federal a través de mecanismos federativos del centro. El estudio trabaja enfoques históricos e institucionales que explican la continuidad y el cambio en los regímenes territoriales. Específicamente, analizamos la pérdida de poder discrecional en el uso de los recursos petroleros evaluando si estos cambios afectaron a la aprobación de la Ley Nacional 12.858 en 2013, que determinó que el gobierno federal, los estados y los municipios deberían gastar su parte de los ingresos petroleros en educación y salud. Mostramos cómo las preferencias subnacionales afectan a las políticas federales, destacando la importancia de la causalidad y del contexto, institucional y político, indicando un regreso a un patrón de gobernabilidad que parecía estar enterrado con el plan de estabilización económica en 1994.

Palabras clave: Federalismo. Ingresos petroleros. Brasil.

Esse texto foi originalmente escrito em Inglês.

Artigo submetido em 27 de dezembro de 2019 e aceito para publicação em 13 de maio de 2020

[Versão traduzida]

DOI: http://dx.doi.org/10.1590/1679-395120190183 


\section{INTRODUÇÃO}

Em 2013, os poderes Executivo e o Legislativo brasileiros aprovaram a Lei $\mathrm{n} 0$ 12.858, determinando que o governo federal, estados e municípios deveriam gastar parte de suas receitas do petróleo em Educação e Saúde. Embora a lei sinalize uma perda na discricionariedade na alocação desses recursos para todos os níveis governamentais, uma análise em maior profundidade do processo revela uma dinâmica federal que beneficia as unidades subnacionais em relação à União, pois gozarão da discricionariedade sobre as receitas petrolíferas por mais tempo.

A literatura mostra que houve, desde a década de 1990, um processo de recentralização federativa no Brasil (ARRETCHE, 2003, 2012). A Constituição de 1988 determinou competências compartilhadas na maioria das políticas e o governo federal aumentou sua participação na formulação de políticas por meio da regulação nacional e das transferências intergovernamentais. Como resultado, a União tem maiores poderes decisórios sobre assuntos que afetam as jurisdições, estando no centro das decisões nacionais na maioria das políticas, enquanto as jurisdições tomam decisões na execução de políticas e regulamentações nacionais (policy-making) (ARRETCHE, 2012). Além disso, a literatura sobre as relações Executivo-Legislativo mostra que, no nível nacional, o Executivo possui importantes poderes legislativos e de agenda, permitindo que ele aprove projetos e mantenha domínio legal. Dentro do Congresso Nacional, parlamentares delegam poder às lideranças partidárias, criando coesão partidária e coalizões consistentes (FIGUEIREDO e LIMONGI, 2007).

Diante dessas especificidades, este estudo busca compreender padrões no processo decisório do Executivo e do Legislativo nacionais, especificamente, na aprovação da Lei no 12.858 em 2013, incluindo se e como os estados e os municípios influenciaram essa decisão, bem como outros fatores condicionantes. 0 estudo das mudanças na alocação de receitas de petróleo no Brasil é particularmente interessante para este debate, pois discute diferentes objetos empíricos e permite a discussão de cenários distintos daqueles colocados pela teorias já consolidadas. Em primeiro lugar, seu objeto não é frequente nos estudos sobre as Políticas Públicas no Brasil, pois trata das políticas do setor petrolífero, o que permite investigar como diferentes conjuntos de instituições e atores setoriais afetam a dinâmica federativa. Em segundo, trata-se de um tipo específico de centralização, a perda do poder discricionário subnacional no uso de recursos petrolíferos. Em terceiro, essa centralização foi aprovada em um contexto de alocação de receitas petrolíferas que beneficiam regiões - estados e municípios - produtoras expondo uma dinâmica que opõe jurisdições produtoras e não produtoras (BRASIL, 2010, 2012, 2013). Em quarto lugar, essa decisão ocorreu quando o apoio popular da Presidente era baixo, uma ruptura em um padrão que prevalecia desde 1994. Além disso, a abordagem é inovadora, pois está focada em processos interativos e como eles impactam a formulação de políticas.

A evolução da política na área petrolífera levou a uma disputa federal por rendas petrolíferas entre jurisdições produtoras e não produtoras. Essa questão eclodiu em 2009, quando o governo federal propôs um novo modelo de exploração de petróleo em águas profundas que não alterou a concentração de receitas de petróleo nos estados e municípios produtores. Depois de uma longa batalha legislativa por uma divisão mais equitativa, que incluiu dois vetos presidenciais e uma derrubada de veto, estados produtores levaram a questão ao Supremo Tribunal Federal em março de 2013.

Metodologicamente, este estudo permite entender se e como o timing e o sequenciamento pode ser um mecanismo causal em um contexto federativo que afeta mudanças. Portanto, utilizam-se dados secundários de debates legislativos entre 2009 e 2013 da Câmara dos Deputados e do Senado, legislação, relatórios governamentais, publicações e cobertura da mídia. Além disso, foram coletados dados primários por meio de entrevistas semiestruturadas entre 2014 e 2015 com membros do Congresso, especialistas e informantes-chave. A lista dos entrevistados está no Anexo 1; os nomes foram suprimidos para preservar seu anonimato. Finalmente, os dados de diferentes fontes foram cruzados para adicionar confiabilidade. Nossa análise baseia-se na discussão da dinâmica histórica e institucional dos sistemas federais, uma vez que as receitas petrolíferas consistem em uma fonte considerável de renda que, reconhecidamente, gera conflitos regionais. A análise se baseia na discussão do federalismo a partir de uma abordagem histórica, fundamentada na literatura sobre federal dynamics que discute os mecanismos de continuidade e mudança nos regimes territoriais, e outras abordagens históricas e institucionais, em especial causalidade no timing, sequenciamento e múltiplas camadas de fatores contextuais na análise de políticas (BENZ e BROSCHEK, 2013; BROSCHEK, PETERSOHN e TOUBEAU, 2018). 


\section{PROCESSO DECISÓRIO, DINÂMICA FEDERATIVA E GOVERNABILIDADE}

A literatura acadêmica sobre o federalismo brasileiro mostra que o país combina características centralizadoras e descentralizadoras. A maioria das políticas, incluindo a política petrolífera, tinha um legado centralizado. Arretche (2012) mostra que houve uma centralização constante desde a década de 1930, que concentrou a formulação de políticas no centro, ao mesmo tempo, em que delegou a implementação de políticas às jurisdições. No entanto, a Constituição de 1988 mudou esse caminho, descentralizando a maioria das políticas. Como resultado, estados e municípios aumentaram sua autonomia política, administrativa e fiscal na formulação de políticas, especialmente, nas políticas sociais, embora a nova Constituição tenha estabelecido responsabilidades compartilhadas com entre entes federativos na maioria das áreas políticas.

No setor petrolífero, a centralização é a norma e o governo federal tem a propriedade do petróleo e a responsabilidade pela extração, produção, transporte e comercialização de petróleo por meio da estatal Petrobras. A Constituição deu à Petrobras o monopólio da exploração nacional de petróleo e deixou a propriedade federal do petróleo inalterada, mantendo o governo federal como principal tomador de decisão. No entanto, transferiu uma parcela significativa das receitas do petróleo para estados e municípios produtores (BRASIL, 1988, 1989). Apesar das reformas orientadas ao mercado da década de 1990 que acabaram com o monopólio estatal de exploração e distribuição de petróleo, a Petrobras permaneceu como principal player na indústria petrolífera (FELIPE, 2010; TROJBICZ, 2016).

Desde meados da década de 1990, o governo federal aumentou seu papel na formulação de políticas em diferentes políticas, particularmente, na Educação, Saúde e Assistência Social por meio da aprovação de normas e regulamentos nacionais, da adoção de subsídios de projetos e da criação de um sistema de equalização para a Educação (ARRETCHE, 2012; FENWICK, 2009; SEGATTO e ABRUCIO, 2018). Algumas mudanças também tiveram implicações nos gastos subnacionais, diminuindo a discricionariedade subnacional, como a Lei de Responsabilidade Fiscal. Isso também afetou as políticas sociais. Na Educação, o Fundo de Manutenção e Desenvolvimento do Ensino Fundamental e de Valorização do Magistério (FUNDEF) e, posteriormente, o Fundo de Manutenção e Desenvolvimento da Educação Básica e Valorização dos Profissionais da Educação (FUNDEB) redistribuíram receitas entre estados e municípios de acordo com as matrículas dos alunos, além de determinar um gasto mínimo para os profissionais da Educação (BRASIL, 1996, 2006). Na Saúde, a legislação nacional determinou gastos mínimos em Saúde para estados e municípios (Emenda Constitucional $n^{\circ} 29$ ) e combinou transferências ao programa nacional de atenção primária à saúde (Norma Operacional Básica, NOB/96) (BRASIL, 1996, 2000). Mais recentemente, a aprovação da Lei no 12.858 seguiu esse caminho de maior centralização, ou seja, diminuindo as discricionárias subnacionais nos gastos.

A literatura afirma que essas mudanças nas políticas públicas estiveram relacionadas às relações intergovernamentais no Brasil, levando a um modelo que combina características centralizadas (poderes de decisão das políticas - policy decision-making - está no governo federal) com características descentralizadas, em que as jurisdições são responsáveis pela execução de políticas nacionais (policy-making). A centralidade do governo federal foi responsável por diminuir as desigualdades entre as jurisdições e garantiu normas comuns em todo o país (ARRETCHE, 2012). Outros autores concordam que, em diferentes políticas, houve um fortalecimento do papel do governo federal como coordenador, mas a autonomia subnacional permanece e influencia a formulação de políticas (BICHIR, SIMONI JUNIOR e PEREIRA, 2020).

Alguns autores propõem uma abordagem diferente para compreender o federalismo e as políticas públicas. Eles argumentam que os arranjos institucionais e a dinâmica federativas são resultado de ideias, políticas, legados políticos, e como moldam as preferências e escolhas dos atores, e da ação política, incluindo coalizões políticas e, neste caso, a articulação dos interesses das entidades territoriais subnacionais no centro ${ }^{1}$. As mudanças são influenciadas por fatores exógenos e endógenos. No caso de fatores exógenos, momentos de conjunturas críticas, influenciados por choques externos, mudam o contexto político e as ideias hegemônicas. No caso de fatores endógenos, a intersecção entre instituições, atores e ideias não necessariamente evoluem no mesmo ritmo e de forma alinhada. Como resultado, podem ocorrer atritos, ou seja, tensões entre os princípios e práticas que estruturam cada nível de governo (BENZ e BROSCHEK, 2013; BROSCHEK, PETERSOHN e TOUBEAU, 2018).

Explicar os fatores que influenciaram as mudanças na atribuição das rendas petrolíferas no Brasil, em especial a aprovação da Lei no 12.858 em 2013, demanda que se discuta o processo decisório no nível nacional e, consequentemente, a governabilidade.

\footnotetext{
${ }^{1}$ Pierson (2004) destaca a importância do legado político, mas ressalta a influência do timing e do sequenciamento, uma vez que decisões anteriores funcionam como um fator de auto reforço, que influencia os interesses e decisões dos atores políticos.
} 
Isso porque a literatura aponta a necessidade de apreender as relações Executivo-Legislativo para melhor compreender o processo decisório nacional.

As análises do sistema político brasileiro avaliam a governabilidade através da intersecção dos efeitos de três características institucionais: presidencialismo, federalismo e sistema multipartidário. Alguns autores mostram que a combinação de um sistema partidário fragmentado com o federalismo leva a problemas de governabilidade na medida em que dispersa o poder de decisão. Outros autores afirmam que essas características institucionais levam a uma paralisia na formulação de políticas devido a conflitos entre o Executivo e o Legislativo no nível nacional. A Presidência reage ao Legislativo usando seu poder de decisão, excluindo outros atores políticos. Essa dinâmica não só afeta a democracia e a representação, mas também resulta em represália pelos atores excluídos, produzindo ingovernabilidade. Essas duas perspectivas foram colocadas em xeque pela dinâmica política que surgiu durante o governo de Fernando Henrique Cardoso. No contexto da estabilização econômica, o Presidente utilizou instrumentos intensamente proativos, resultando em um resultado positivo na governabilidade. Figueiredo e Limongi (2007) são exemplos de autores dentro deste último grupo (PALERMO, 2000).

No entanto, é importante notar que essas abordagens se baseiam excessivamente em características institucionais do Brasil para explicar os resultados da governabilidade, ao mesmo tempo em que pouco incluem aspectos da ação política, ou seja ênfase nas instituições em detrimento da agência. Nesse sentido, alguns críticos apontam para a dependência excessiva de regras formais em detrimento da análise do processo político, em que atores e interesses têm maior prevalência. Além disso, durante todo o período democrático, iniciado em 1988, essas instituições com características centrífugas estiveram presentes, enquanto, durante o período de maior governabilidade, há influência da agência de natureza centrípeta. Em suma, considerando que as características institucionais foram constantes, e os padrões de tomada de decisão mudaram ao longo do tempo, isso indica, como mínimo, a necessidade de uma análise histórica para entender se há alguma variável que não foi considerada e que influenciou a variação da governabilidade ao longo do tempo (ARMIJO, LESLIE, FAUCHER et al., 2006; PALERMO, 2016).

Seguindo essa lógica, buscamos contribuir para esse debate analisando as intersecções entre instituições e agências por meio de análise histórica que procura responder algumas questões fundamentais. A aprovação da Lei no 12.858 em 2013 foi resultado de uma mudança na dinâmica federativa no Brasil? Se sim, como se relaciona com padrões de governabilidade de continuidade e mudança? E quais fatores, exógenos e endógenos, explicam essa mudança? Legados de políticas, ideias e coalizões políticas?

\section{A DISPUTA FEDERATIVA POR RENDAS PETROLÍFERAS}

Seguindo o regime militar, quando rendas petrolíferas não eram destinadas a jurisdições subnacionais, a Constituição de 1988 determinou a distribuição dessas receitas priorizando as regiões produtoras. A Lei no 7.990/1989 regulamentou esse arranjo, beneficiando jurisdições geograficamente próximas aos campos de petróleo, principalmente, o Estado do Rio de Janeiro e algumas de suas cidades litorâneas. A defesa dessa determinação menciona a troca dos ganhos do ICMS de petróleo e derivados de petróleo: no Brasil, esse imposto é creditado ao estado de origem, o que, no caso do petróleo, favoreceria os estados produtores. Portanto, na Constituição, a cobrança do ICMS foi revertida para estados de destino, o que compõe uma troca de receitas fiscais por rendas petrolíferas (DIAS e RENAULT, 2013; FERRARI, 2013).

Em meados da década de 1990, o Presidente Fernando Henrique Cardoso promoveu reformas para abertura do mercado em diversos setores econômicos. A reforma do petróleo foi incorporada pela Lei no 9.478 em 6 de agosto de 1997, a chamada "Lei do Petróleo". Para aprovar a nova regulamentação, foi necessário aprovar duas emendas constitucionais. A primeira, a Emenda no 6, flexibilizou as condições para determinar se uma empresa é nacional, e a segunda, a Emenda no 9, acabou com o monopólio da Petrobras sobre a exploração de hidrocarbonetos no Brasil. Essas duas Emendas Constitucionais fundamentaram a liberalização da exploração e produção de petróleo e gás no país e, assim, permitiram a atividade de empresas petrolíferas estrangeiras no Brasil (TROJBICZ, 2016).

Como resultado, a Petrobras deixou de administrar o setor. Esse atributo foi transferido para a nova agência reguladora, a Agência Nacional do Petróleo, Gás Natural e Biocombustíveis (ANP). Além disso, a estatal foi liberada das regras de controle do setor público em compras e licitações, a fim de dar mais agilidade para competir com outras empresas que ingressaram no mercado brasileiro. Finalmente, em 1999, a empresa passou por reestruturação organizacional. Essas mudanças precederam 
um aumento substancial no volume de petróleo extraído no Brasil, que, juntamente com a elevação dos preços internacionais a partir dos anos 2000, resultaram em aumento considerável na importância do setor: sua participação no PIB brasileiro passou de 2,8\% em 1997 para 10,5\% em 2005. Como mencionado, este foi um período de enorme expansão do valor internacional do petróleo e gás. Enquanto o volume de petróleo extraído dobrou entre 1998 e 2009, o valor médio do barril de petróleo aumentou de forma ainda mais extraordinária: seu preço médio passou de US\$13,56 para US\$ 83,46 entre 1998 e 2008. Como resultado, o faturamento das empresas de exploração de petróleo no Brasil aumentou de $\mathrm{R} \$$ 15,3 bilhões em 1998 para $\mathrm{R} \$ 97,8$ bilhões em 2008, embora tenha diminuído para $\mathrm{R} \$ 73,8$ bilhões em 2009, em função da crise global (FELIPE, 2010).

As participações governamentais sobre as rendas petrolíferas acompanharam esse crescimento e passaram de $\mathrm{R} \$ 1,7$ bilhão em 1998 para R\$ 25,4 bilhões em 2008. Aproximadamente $90 \%$ desses recursos, que correspondem aos royalties e participações especiais, foram compartilhados com estados e municípios.

Em 2007, a Petrobras descobriu enormes reservatórios de petróleo na plataforma continental, em específico no que se denominou como o polígono do pré-sal. A partir dessa descoberta, que se constitui como uma influência exógena, motivou estudos que apontaram para a necessidade de um novo marco regulatório para explorar o petróleo desta região, com base em seu menor risco exploratório. Os resultados deste estudo geraram os projetos de lei do novo marco legal, para regular essas atividades exploratórias. Segundo membros do Congresso entrevistados, parlamentares das jurisdições não produtoras estavam insatisfeitos com a distribuição federativa dos recursos petrolíferos, ainda antes do Congresso Nacional receber o projeto do Executivo federal- projetos de lei no 5.938, 5.939, 5.940 e 5.941 - de 1ㅇ de setembro de 2009. Portanto, durante o processo de discussão legislativa, eclodiu importante disputa federativa, na qual jurisdições menos favorecidas pelas receitas de royalties tentaram impor uma distribuição territorial mais equitativa desses recursos (TROJBICZ, 2019). Isso evidencia o atrito entre as camadas institucionais territoriais e sociais. ${ }^{2}$

A disputa federativa pelos aluguéis de petróleo começou na Câmara Baixa, com a Emenda Ibsen (Emenda no 387 ao PL no 5.938/2009) O Senado então combinou dois dos projetos de lei, modificando alguns aspectos da Emenda Ibsen, que foi substituída pela Emenda Pedro Simon. Essa última utilizava recursos da União para ressarcir as jurisdições produtoras pelas perdas decorrentes da redistribuição dos recursos. Esse material retornou à Câmara dos Deputados e foi aprovado como Lei no 12.351 de 22 de dezembro de 2010.

Em seguida, o Presidente Lula vetou o artigo que visava modificar a distribuição dos royalties por meio da mensagem 707/10 e enviou um novo projeto de lei ( $n$ o 8.051) em 31 de dezembro de 2010, no último dia de seu governo. 0 motivo apontado pelo Executivo para o veto estava relacionado à necessidade da União ressarcir as perdas das jurisdições confrontantes. No entanto, segundo os entrevistados, o poder de influência do governador do Rio de Janeiro, Sérgio Cabral, e dos membros do Congresso do Rio de Janeiro, filiados ao PMDB, o maior partido do Congresso, também influenciaram esse processo. ${ }^{3}$

Como mencionado, o Senado fundiu os dois projetos de lei, o que permitiu ao Senado utilizar um dos projetos da Câmara dos Deputados para reiniciar a questão. Parlamentares insatisfeitos com o veto do presidente em relação à distribuição de royalties direcionaram o projeto de lei do Senado no 448/2011 à Câmara dos Deputados como o projeto de lei no 2.565/2011 e aprovado na forma da Lei no 12.734, de 30 de novembro de 2012. Mais uma vez, o Executivo federal vetou a distribuição de recursos e o Congresso derrubou o veto em 6 de março de 2013. Isso motivou uma Ação Direta de Inconstitucionalidade, movida pelos estados confrontantes (Rio de Janeiro, Espírito Santo e São Paulo) no Supremo Tribunal Federal. Em 18 de março de 2013, um dos juízes do Supremo Tribunal Federal suspendeu o efeito da Lei no 12.734/2012, e manteve a atribuição da maior parte dos recursos para os estados e municípios confrontantes. Esse processo, poucos meses antes dos debates sobre o uso das rendas petrolíferas, condicionou o processo e a aprovação da Lei no 12.858, indicando a importância do timing e do sequenciamento nesse processo de mudança.

\footnotetext{
${ }^{2}$ Ibsen Pinheiro (PMDB-RS) e Humberto Souto (PPS-MG) foram entrevistados para esta pesquisa em junho de 2014 e fevereiro de 2015 , respectivamente. Eles são os autores da emenda Ibsen.

${ }^{3}$ Dois dos consultores legislativos especializados em Minas e Energia, entrevistados para esta pesquisa, fizeram tal afirmação.
} 


\section{A influência das jornadas de junho sobre as mudanças na distribuição da receita de petróleo}

Em junho de 2013, grandes protestos de rua ocorreram no Brasil e modificaram dinâmicas importantes do sistema político. Esses protestos se constituem como um choque externo, que começaram como uma mobilização em resposta ao aumento da tarifa do transporte público na Cidade de São Paulo, mas ganharam notoriedade pela repressão policial e destruição de bens, com um aumento substancial de participantes. A partir daí, o movimento absorveu reivindicações adicionais, incluindo o descontentamento com a prestação de serviços públicos e a corrupção da classe política (SINGER, 2013). Essas manifestações mostraram o descontentamento popular em relação a temas nacionais fundamentais e impactaram a popularidade dos políticos em geral, mas em especial a da Presidente Dilma Rousseff (DATAFOLHA, 2013).

A Presidente reconheceu essas reivindicações de forma simbólica propondo cinco pactos nacionais relacionados às políticas de Saúde, de Educação e de Transporte, à responsabilidade fiscal e à reforma política, incluindo o combate à corrupção, exigindo a aprovação do Congresso Nacional. A Presidente afirmou que $100 \%$ das receitas de petróleo seriam empregadas em Educação para atingir ou superar a meta de $10 \%$ do investimento do PIB na área, objetivo determinado pelo Plano Nacional de Educação, discutido no Senado Federal.

Essas mudanças na distribuição das receitas petrolíferas haviam sido introduzidas em dois de maio, por meio do Projeto de Lei no 5.500 (PL no 5.500/2013), antes dos protestos nacionais. Portanto, a existência de tal projeto de lei antes da turbulência política foi estratégica para a resposta da Presidente, atuando como um fator de auto reforço, que teve implicações nas decisões dos atores políticos. O sequenciamento foi fundamental nesse processo, pois as manifestações se colocam no centro do debate político. O Congresso Nacional também interrompeu as férias parlamentares e começou a votar propostas em resposta a essas reivindicações, entre elas o já citado PL no 5.500/2013. ${ }^{4}$

O sistema brasileiro de rendas petrolíferas é complexo, pois envolve três regimes fiscais em que variam os impostos cobrados e suas alíquotas, dependendo das especificidades da exploração. A distribuição federal dessas rendas também varia. Como essa fragmentação impacta o entendimento das mudanças que o sistema político operava no projeto de lei, é importante delinear brevemente suas complexidades.

Existem três regimes fiscais para exploração de petróleo no Brasil. O regime de concessão (Royalties and taxes $-R / T$ ), criado pela Lei no 9.738/1997, é aplicado atualmente em áreas que não estejam compreendidas no polígono do pré-sal. No entanto, muitas áreas que foram concedidas antes da descoberta dessas reservas foram realizadas com o modelo de concessão. Portanto, há muitos campos na área do pré-sal que são exploradas com esse modelo. 0 regime de partilha (Profit sharing - PSC), introduzido pela Lei no 12.351/2010, é aplicado exclusivamente às áreas do pré-sal. Esse sistema inclui a divisão da produção de petróleo, o chamado petróleo-lucro (profit oil), entre concessionária e estatal. A Cessão Onerosa ${ }^{5,6}$ é o terceiro sistema fiscal em operação no Brasil, criado pela Lei no 12.276/2010, por meio do qual a União transfere onerosamente para a Petrobras cinco bilhões de barris de petróleo em campos especificados do pré-sal.

Existem quatro tipos de participações governamentais: royalties, participações especiais, bônus de assinatura e pagamento por ocupação e retenção de área. Essas taxas são compartilhadas entre entes federativos de formas diferentes, pois os royalties e participações especiais são compartilhados com os entes subnacionais em proporções variadas, dependendo da exploração, enquanto o bônus de assinatura e o pagamento pela ocupação e retenção da área permanecem exclusivamente com a União. A concessão inclui todas as quatro taxas. A partilha não cobra participação especial e o petróleo lucro a substitui.

Além disso, as alíquotas de royalties e a distribuição federal dos recursos variam de acordo com o regime fiscal, a produtividade do campo e a localização. Os sistemas de concessão cobram de 5 a 10\%, enquanto a partilha cobra 15\%, com distribuições variadas. No sistema de concessão, a distribuição federativa também varia dependendo se a exploração é offshore ou onshore. o Quadro 1 resume os sistemas de exploração de petróleo e suas taxas no Brasil.

\footnotetext{
${ }^{4}$ Deputado Mauro Mendonça Filho (DEM-PE): em discurso na Sessão Deliberativa Ordinária, 25 de junho de 2013, p. 26356.

Deputado André Figueiredo (PDT-CE) em discurso na Sessão Deliberativa Ordinária, 25 de junho de 2013, p. 26192.

Deputado Mauro Benevides (PMDB-CE) em discurso na Sessão Deliberativa Ordinária, 25 de junho de 2013, p. 26123-4.

Deputado Leonardo Monteiro (PT)-MG) em discurso sobre a Sessão Deliberativa Ordinária, 25 de junho de 2013, p. 26141.

Deputado Mário Heringer (PDT-MG) em discurso na Sessão Deliberativa Ordinária, 10 de julho de 2013, p. 29764.

Deputada Iracema Portella (PP-PI) em discurso na Sessão Deliberativa Ordinária, 10 de julho de 2013, p. 29828.

${ }^{5}$ Para obter uma descrição mais detalhada dos sistemas de concessão e partilha, ver Humpreys, Sachs e Stiglitz (2007).

${ }^{6}$ A Lei 13.365/2016 determinou o fim da participação obrigatória de $30 \%$ da Petrobras nos consórcios que exploram campos do pré-sal. Além disso, permitiu que outras petroleiras fossem as operadoras do consórcio, o que antes era restrito à estatal brasileira.
} 


\section{Sistemas de exploração de petróleo e suas taxas no Brasil}

\begin{tabular}{|l|l|l|l|l|}
\hline \multicolumn{2}{|c|}{ Royalties } & \multicolumn{1}{|c|}{$\begin{array}{c}\text { Participações } \\
\text { Especiais }\end{array}$} & $\begin{array}{c}\text { Bônus de } \\
\text { assinatura } \\
\text { por Ocupação e } \\
\text { Retenção de Área }\end{array}$ \\
\hline Concessão & De $5 \%$ a $10 \%$ & $\begin{array}{l}\text { Definido com base na produtividade } \\
\text { do campo de petróleo }\end{array}$ & $\begin{array}{l}\text { Critério para definir o } \\
\text { vencedor do leilão }\end{array}$ & Pago anualmente \\
\hline Partilha & $15 \%$ & Substituído pelo lucro petróleo & Valor fixo & Isento \\
\hline Cessão Onerosa & De $5 \%$ a $10 \%$ & Isento & Isento & Isento \\
\hline
\end{tabular}

Fonte: Elaborada pelos autores.

Além disso, a exploração de petróleo abrange alguns marcos temporais. O primeiro é a assinatura do contrato, após a qual a concessionária inicia a prospecção e, se bem sucedida, emite a declaração de comercialidade. Finalmente, quando o petróleo é produzido, os impostos são recolhidos de acordo ao regime fiscal. Para entender o processo legislativo em análise, o timing é relevante, pois dependendo do marco temporal empregado, o uso obrigatório dos recursos para a Educação começará mais cedo ou mais tarde.

O Projeto de Lei no 5.500 propôs utilizar as receitas de petróleo em Educação, ancorados na ideia de que o aumento dos gastos nesta política melhoraria seus resultados. Trata-se de um processo de centralização federativa, à medida que os gastos com recursos passam a ser determinados pelo centro. No entanto, como vimos, os recursos originados na exploração de petróleo são plurais e fragmentados, o que permite multiplicar as possibilidades de negociação a fim de beneficiar interesses específicos. Portanto, a natureza não monolítica dos recursos permite um resultado com mais nuances, em contraposição a uma visão de que o resultado significa vitória da União. Nesse sentido, a forma como o Projeto de Lei no 5.500 evoluiu sinaliza uma disputa de poder bastante complexa, na qual o centro não é o vencedor. Para acompanhar essas influências, essa análise destacará os elementos do projeto de lei para compreender todas as implicações envolvidas nas decisões, que indicam como as camadas institucionais territoriais conflitam com as ideias subjacentes a ela.

O PL no 5.500 contou com quatro fontes de recursos que indicam a influência das coalizões sociais sobre o Projeto de Lei. A primeira incluiu receita originada em pagamentos de royalties aos três níveis de governo (União, estados e municípios) nos regimes fiscais de concessão e partilha, para contratos em vigor após dois de dezembro de 2012. A lei também não se limita às receitas de explorações no pré-sal, já que também vale para áreas fora do pré-sal. No entanto, apenas as áreas que foram concedidas após a data estabelecida teriam recursos não discricionários. Em termos concretos, devido ao longo intervalo entre contrato e produção comercial, a Educação será beneficiada com recursos significativos apenas até cerca de 2022 a 2027, não importando o nível de governo considerado.

Em segundo lugar, o Projeto de Lei também propôs que 50\% dos rendimentos das receitas do Fundo Social do Pré-Sal fossem destinados à Educação. Os fundos de poupança não são incomuns na gestão dos recursos petrolíferos e há muitas maneiras de lidar com as receitas. O modelo "pássaro na mão" (bird in hand), que regula o fundo petrolífero norueguês, só paga dividendos sobre os rendimentos das receitas, o que favorece as gerações futuras em detrimento das atuais. O Fundo Social do Pré-Sal, aprovado na Lei 12.351/2010, seguiu essa abordagem intergeracional, sendo abastecido com receitas originárias dos royalties e participações especiais destinadas apenas à União nos regimes fiscais de concessão e cessão onerosa e também localizados apenas na área do Pré-sal. No entanto, os royalties obtidos nos contratos de partilha não comporiam o fundo social. Em suma, a proposta do governo federal pode ser caracterizada como orientada ao futuro, pois não alivia as necessidades de recursos nos próximos 15 anos.

Em terceiro lugar, a Câmara dos Deputados fundiu o Projeto de Lei no 5.500/2013 com o Projeto de Lei no 323, proposto em março de 2007. Com isso, incluiu-se a Saúde como destino de $25 \%$ dos recursos. Além disso, os membros do Congresso estavam descontentes com o lapso de tempo prolongado para o início da destinação dos recursos. O deputado Izalci observou: "Não adianta se aprovar projeto para a Educação agora que só valerá dentro de oito anos, dez anos. O recurso tem de ser aplicado já. E é isso o que nós pretendemos votar nesta Casa. Não adianta se fazer discurso lá fora, e o projeto aqui ser totalmente diferente".? Dessa forma, os deputados mudaram as fontes de receita para responder à necessidade de aumentar os recursos no curto prazo.

7 Deputado Izalci (PSDB-DF), em discurso na Sessão Deliberativa Ordinária, 25 de junho de 2013, p. 25896 
Com isso, o uso obrigatório de recursos federais e subnacionais tornou-se mais abrangente, já que as mudanças que os representantes fizeram ao Projeto de Lei permitiram a apropriação anterior dos recursos. Royalties e Participação Especial obtidos pelo governo federal, estados e municípios em contratos nos três regimes fiscais - concessão, cessão onerosa e partilha de produção - em todos os territórios offshore com declaração de comercialidade após dezembro de 2012 seriam obrigatoriamente aplicados em Educação e Saúde (artigo 2º, incisos I e II).

O deputado André Figueiredo mencionou o impacto financeiro dessa diferença:

Vários contratos foram licitados no ano de 2001, no ano de 2003 e no ano de 2005. A título de exemplo, dos sete blocos mais promissores licitados em 2000 e $2001 . . . . .$. na região do pré-sal da Bacia de Santos, apenas dois campos, Lula e Sapinhoá, já tiveram declarada a sua comercialidade. As áreas de Bemte-vi, Parati e Caramba somente deverão entrar em produção comercial depois de decorridos mais de 16 anos da licitação. As áreas licitadas após 2001 deverão demorar mais tempo ainda para entrar em operação comercial. Por isso, colocamos que todas aquelas, inclusive essas licitadas em 2001, que não tiveram ainda decretada a sua comercialidade, [para que elas] possam também ir para a educação, mesmo já tendo sido contratadas, mas ainda não decretada a sua comercialidade. ${ }^{8}$

Em quarto lugar, a combinação de ambos os projetos levou a uma mudança significativa no uso dos recursos do Fundo Social, uma vez que $50 \%$ dos recursos, e não os rendimentos, seriam destinados à Educação (artigo 20, inciso III). Os recursos do Fundo Social também foram incrementados com recursos do governo federal, pois o substitutivo indicou que os royalties e a participação especial dos regimes de concessão localizados nas áreas do Pré-Sal para contratos antes de dezembro de 2012 seriam destinados ao Fundo Social do Pré-Sal (artigo 20, inciso III). Além disso, os recursos da União provenientes da unitização seriam destinados à educação pública (artigo $2^{\circ} \circ$, inciso IV). ${ }^{9}$

Essa proposta foi ao Senado, no qual sofreu novas mudanças em critérios diferenciados para os gastos dos governos federal e subnacionais. A referência à declaração de comercialidade como marco para a destinação dos recursos à Educação e à Saúde foi mantida para os recursos da União, enquanto os recursos subnacionais (estados e municípios) teriam o marco da assinatura do contrato. Isso significa que os recursos subnacionais levarão mais tempo para que seu uso deixe de ser discricionário, enquanto o recurso da União será destinado aos fins estabelecidos antes.

A ideia era evitar a judicialização da matéria, que ocorreu com as mudanças na redistribuição de royalties em março do mesmo ano, indicando mais uma vez o impacto do tempo e do sequenciamento, ou seja, mudanças anteriores influenciaram as decisões dos atores políticos. O Senado queria evitar a judicialização com a mudança na destinação dos recursos da individualização dos campos de petróleo à Saúde e Educação e a determinação de um percentual mínimo de participação da União nos contratos de partilha de produção, temas que poderiam ser questionados em juízo. ${ }^{10}$

Outra mudança no Senado que aumentou o uso obrigatório da receita do governo federal está relacionada aos royalties e à participação especial dos campos de concessão localizados nas áreas do Pré-sal. A totalidade desses recursos foram direcionados ao fundo social e $50 \%$ do principal do fundo destinado à educação. Isso se soma aos rendimentos do fundo, já destinados a gastos em Educação e Saúde. Por fim, o substitutivo do Senado indicou que os recursos petrolíferos poderiam ser empregados para salários dos professores, que é um gasto de custeio, rompendo a determinação de somente usar os recursos para gastos de investimento. ${ }^{11}$

O Senado retornou a proposta revisada à Câmara dos Deputados, que a aprovou. No entanto, discursos de membros do Congresso indicam que houve uma batalha entre grupos que defendiam uma apropriação mais imediata dos recursos petrolíferos para a educação e a saúde, contra outro grupo que pretendia adiar. Venceu o adiamento. Um dos membros da Câmara dos Deputados mencionou que havia um acordo entre os líderes partidários para aprovar o projeto do Senado. ${ }^{12}$

\footnotetext{
${ }^{8}$ Deputado André Figueiredo (PT-RS) em discurso na Sessão Deliberativa Ordinária, 25 de junho de 2013, p. 26193. Tradução livre do autor para o inglês.

${ }^{9}$ Não tão relevante do ponto de vista federativo, mas importante mencionar, o PLC propôs uma participação mínima de $60 \%$ no lucro petróleo para a União nos contratos de 'partilha.

${ }^{10}$ Individualização é um termo utilizado no setor de petróleo para descrever o processo aplicado quando diferentes concessões acessam o mesmo campo. A individualização do campo determina a parcela de cada participante na reserva total de petróleo. Com ela, aumenta a arrecadação de rendas porque campos maiores pagam mais impostos por serem mais produtivos.

${ }^{11}$ Senador Randolfe Rodrigues (PSOL-AP) em discurso na Sessão Deliberativa Ordinária, 2 de julho de 2013, p. 41862.

${ }^{12}$ André Figueiredo (PDT-CE), discurso na Sessão Ordinária na Câmara dos Deputados, 10 de julho de 2013 , p. 29912.
} 
O texto da Lei no 12.858/2013 refere-se aos artigos 214 e 196 da Constituição Federal de 1988, a fim de justificar os gastos de recursos em Educação e Saúde. Ainda aludindo aos deveres constitucionais, o destino de recursos para a Educação busca cumprir a Emenda Constitucional no 59 de 2009, que estabelece o investimento na área como percentual do PIB. $O$ destino dos royalties para a Educação foi baseado nessa perspectiva, como evidenciado pelo texto do Plano Nacional de Educação (Lei no 13.005, de 25 de junho de 2014), que indica em seu anexo o uso de recursos petrolíferos para atingir sua meta número 20: "aumentar o investimento público em educação pública para atingir pelo menos 7\% (sete por cento) do Produto Interno Bruto - PIB do País no 5o (quinto) ano desta Lei e, no mínimo, equivalente a 10\% (dez por cento) do PIB no final da década" (Lei 13.005, de 25 de junho de 2014, Anexo, meta 20).

Em termos mais detalhados, a Lei no 12.858 determina quais parcelas da participação do Estado nos recursos financeiros originados na exploração de petróleo e gás natural serão destinadas às áreas de Saúde e Educação - com ênfase na educação infantil, ensino fundamental e médio. Essa transferência se justifica na lei pela necessidade de atender às demandas constitucionais na prestação de serviços públicos e, para isso, a nova lei modifica a legislação vigente que remonta a 1989, a Lei no 7.990, de 28 de dezembro de 1989.

A Lei no 12.858 determina cinco fontes de recursos. Em primeiro lugar, os recursos dos royalties e participações especiais atribuídas à União, cuja declaração de comercialização sobre explorações offshore entrou em vigor após três de dezembro de 2012. Todas essas receitas devem ser destinadas à Educação e à Saúde. A segunda fonte diz respeito aos royalties e participações especiais obtidos por estados, municípios e Distrito Federal. Essa alocação diz respeito apenas aos contratos firmados após 3 de dezembro de 2012, o que implica uma diminuição dos recursos a serem recebidos no curto prazo em relação à definição válida para os recursos obtidos pela União. A terceira fonte estabelece que $50 \%$ dos recursos recebidos pelo Fundo Social do Pré-Sal devem ser destinados à Educação e à Saúde. A quarta fonte de recursos refere-se às originárias em acordos de individualização da produção. A quinta origina-se na parcela da União dos royalties e participações especiais de petróleo extraído do pré-sal com exploração regida por contratos de concessão e contempla participações que tenham declaração comercial até três de dezembro de 2012.

Anteriormente, a aplicação desses recursos era discricionária e determinada pela referida Lei no 7.990/89. A única condição para a utilização dos recursos pela regra anterior era não aplicá-los para pagar dívidas públicas e permanentes (Lei no 12.858). Portanto, os recursos que antes eram gastos com alto grau de autonomia são agora determinados nacionalmente, reduzindo a discricionariedade decisória dos governos subnacionais para seu uso.

\section{CONCLUSÕES}

Nossa análise aponta a importância dos protestos ocorridos em junho de 2013, como fator externo que desencadeou mudanças, ao mesmo tempo em que influenciou a construção de consensos sobre a importância da melhoria das políticas de Saúde e de Educação. Além disso, afetou a popularidade dos governos e criou um ponto de inflexão no padrão de governabilidade brasileiro. Em específico, abalou a capacidade da Presidente em impor suas preferências sobre o Congresso Nacional, o que criou as condições para seu impeachment. Os protestos criaram uma conjuntura crítica, a partir da qual iniciou-se uma nova trajetória. Nesse sentido e alinhado com a teoria institucionalista, as manifestações não determinaram a aprovação da nova legislação, mas criaram uma ruptura que permitiu o início desse processo.

Essa nova trajetória pode indicar o retorno a um padrão de governabilidade que parecia estar enterrado com o plano de estabilização econômica em 1994. O padrão vigente apresenta configuração institucional que atribuiu poderes ao Presidente e aos líderes partidários. No entanto, a configuração vigente desde 2013 pode indicar a importância de outros aspectos como fundamentais para determinar a governabilidade no Brasil.

Além disso, argumentamos que o timing e o sequenciamento desempenham um papel importante no desdobramento de novos eventos. A judicialização da distribuição federativa das rendas petrolíferas impactou a decisão dos parlamentares sobre aspectos relacionados ao investimento obrigatório dessas receitas em Educação e Saúde. Especificamente, em março de 2013, a decisão do Legislativo federal para que a distribuição regional dessas receitas se tornasse mais equitativa das rendas 
petrolíferas passou do Congresso Nacional para o Supremo Tribunal Federal, dando lugar a uma dinâmica decisória distinta, em que a decisão não está mais na alçada dos políticos.

Como mostram os debates no Congresso Nacional, o investimento obrigatório dos recursos petrolíferos em áreas de políticas públicas específicas também resultou dos protestos ocorridos no Brasil em junho de 2013. Ainda, o conflito por essas receitas, que precedeu a questão da discricionariedade, contrapunha os estados produtores e não produtores. Nesse sentido, não se configurava como um conflito entre governos federal e subnacionais - tipo de disputa mais frequente na literatura sobre o federalismo. Os protestos foram importantes na disseminação de ideias, mas não explicam completamente essa mudança, já que ela resultou da combinação de um arcabouço institucional que dá um papel proeminente ao Executivo e Legislativo, do timing e do sequenciamento que influenciaram as decisões dos atores políticos.

Ademais, o resultado da política destaca os limites de uma abordagem dicotômica sobre o federalismo, pois uma análise mais minuciosa mostra que o processo em análise não pode ser entendido na base de um único eixo de centralização-descentralização. Nesse sentido, as contingências em relação ao setor da política específica devem ser avaliadas para compreender as particularidades da questão. Nesse caso, isso significa entender como os marcos dos contratos de petróleo impactaram a decisão tomada nos governos federal e estaduais sobre o uso das rendas dos hidrocarbonetos.

Mais pesquisas são necessárias para entender como a perda de popularidade de um Presidente afeta a sua capacidade de impor preferências sobre o Congresso Nacional. Além disso, à medida que o tempo evolui, o efeito da Lei no 12.858 aumenta e mais recursos devem ser direcionados a essas políticas sociais fundamentais. Monitorar esse processo pode ser interessante para uma melhor compreensão sobre a forma como o sistema político reage aos impactos desse choque de recursos. Finalmente, a literatura de recursos naturais chama atenção para os perigos que esse tipo de riqueza representa para a ação política, o que desafia a resiliência das estruturas institucionais a ações de grupos de interesse. 


\section{REFERÊNCIAS}

ARMIJO, L. E.; FAUCHER, P.; DEMBINSKA, M. Compared to what? Assessing Brazil's political institutions. Comparative Political Studies, v. 39, n. 6, p. 759-786, 2006.

ARRETCHE, M. Democracia, federalismo e centralização no Brasil. Rio de Janeiro: Editora Fiocruz/Editora FGV, 2012.

ARRETCHE, M. Quem taxa e quem gasta: a barganha federativa na federação brasileira. Revista de Sociologia e Política, Curitiba, v. 24, p. 69-85, 2005.

ARRETCHE, M. Financiamento federal e gestão local de políticas sociais: O difícil equilíbrio entre regulação, responsabilidade e autonomia. Ciência \& Saúde Coletiva, v. 8, n. 2, p. 331-345, 2003.

BALKYS, H.; BROWN, D. Policy coordination in federal systems: comparing intergovernmental processes and outcomes in Canada and the United States. Publius, v. 40, n. 3, p. 484-507, 2010.

BANTING, K. G. Canada: nation-building in a federal welfare state. In: OBINGER, H.; LEIBFRIED, S.; CASTLES, F. G. (Eds.). Federalism and the welfare state: New world and European experiences. New York: Cambridge University, 2005. p. 89-137.

BANTING, K. G. Social citizenship and federalism: is a federal welfare state a contradiction in terms? In: GREER, S. L. (Ed.). Territory, democracy and justice: Regionalism and federalism in Western Democracies. New York: Palgrave MacMillan, 2006. p. 44-66.

BÉLAND, D.; LECOURS, A. Federalism, nationalist politics, and social policy: How ideas and institutions shape federal dynamics. In: BENZ, A.; BROSCHEK, J. (Eds.). Federal dynamics: Continuity, change, and the varieties of federalism. Oxford: Oxford University Press, 2013. p. 209-228.

BÉLAND, D. et al. Fiscal Federalism and Equalization Policy in Canada. Toronto: University of Toronto Press, 2017.

BENZ, A.; BROSCHEK, J. Federal dynamics: Introduction. In: BENZ, A.; BROSCHEK, J. (Eds.). Federal dynamics: Continuity, change, and the varieties of federalism. Oxford: Oxford University Press, 2013. p. 1-26.

BICHIR, R.; SIMONI JUNIOR, S.; PEREIRA, G. Sistemas Nacionais de Políticas Públicas e seus efeitos na implementação: O caso do Sistema único de Assistência Social (Suas). Revista Brasileira de Ciências Sociais, v. 35, n. 102, p. 1-23, 2020.

BRASIL. Emenda Constitucional no 29, de 13 de setembro de 2000. Altera os arts. 34, 35, 156, 160, 167 e 198 da Constituição Federal e acrescenta artigo ao Ato das Disposições Constitucionais Transitórias, para assegurar os recursos mínimos para o financiamento das ações e serviços públicos de saúde. Brasília, DF: Congresso Nacional, 2000.

BRASIL. Lei $\mathbf{n}$ 9 9.394, de 20 de dezembro de 1996. Estabelece as diretrizes e bases da educação nacional. Brasília, DF: Congresso Nacional, 1996.

BRASIL. Lei no 11.494, de 20 de junho de 2007. Regulamenta o Fundo de Manutenção e Desenvolvimento da Educação Básica e de Valorização dos Profissionais da Educação - FUNDEB, de que trata o art. 60 do Ato das Disposições Constitucionais Transitórias; altera a Lei n o 10.195, de 14 de fevereiro de 2001; revoga dispositivos das Leis n os 9.424, de 24 de dezembro de 1996, 10.880, de 9 de junho de 2004, e 10.845, de 5 de março de 2004; e dá outras providências. Brasília, DF: Congresso Nacional, 2006.

BRASIL. Portaria no 2.203, de 5 de novembro de 1996. Brasília, DF: Ministério da Saúde, 1996.

BROSCHEK, J.; PETERSOHN, B.; TOUBEAU, S. Territorial Politics and Institutional Change: A Comparative-Historical Analysis. Publius, v. 48, n. 1 , p. $1-25,2018$.

BURGUESS, M.; GRESS, F. Symmetry and asymmetry revisited. In: AGRANOFF, A. (Ed.). Accommodating Diversity: Asymmetry in federal states. Baden-Baden: Homos Verlagsgesehschaft BadenBaden, 1999. p. 43-56.

DARDANELLI, P. et al. Dynamic De/Centralisation in Federations: Comparative Conclusions. In: WORLD CONGRESS INTERNATIONAL POLITICAL SCIENCE ASSOCIATION, 24., 2016, Poland. Proceedings... Poland: IPSA, 2016.

DATAFOLHA. Avaliação da presidente Dilma Rousseff. 2013. Disponível em: <http://media.folha.uol.com.br/datafolha/2013/07/01/avaliacaodilma.pdf $>$. Acesso em: 05 out. 2020.

DIAS, G.; RENAULT, A. A concentração de recursos na União e as perdas das regiões produtoras. In: GIAMBIAGI, F.; LUCAS, L. P. V. (Eds.). Petróleo: Reforma e Contrarreforma do setor petrolífero. Rio de Janeiro: Elsevier Editora, 2013. p. 153-178

FIGUEIREDO, A.; LIMONGI, F. Instituições Políticas e Governabilidade: Desempenho do Governo e Apoio Legislativo na Democracia Brasileira. In: MELO, C. R.; SAÉZ, M. A. (Eds.). A Democracia Brasileira: Balanço e Perspectivas para o Século 21. Belo Horizonte: Editora UFMG, 2007.

FELIPE, E. S. Mudanças Institucionais e Estratégias Empresariais: a trajetória e o crescimento da Petrobrás a partir da sua atuação no novo ambiente competitivo (1997-2010). 2010. Tese (Doutorado em Economia) - Universidade Federal do Rio de Janeiro, Rio de Janeiro, 2010.

FENWICK, T. B. Avoiding Governors: The Success of Bolsa Família. Latin American Research Review, v. 44, n. 1, p. 102-131, 2009.

FERRARI, D. A. Descentralização Fiscal e Repartição da Receita Pública: o FPE na Constituinte de 1988. 2013. Dissertação (Mestrado em Ciência Política) - Universidade de São Paulo, São Paulo, 2013.

GOBETTI, S. W.; SERRA, R. V. Novo Marco Regulatório do Petróleo: desafios na transição do regime de concessão para o regime de partilha. In: PRÊMIO FINANÇAS PÚBLICAS DO TESOURO NACIONAL, 16., 2011. Anais... Brasília, DF: ESAF, 2011.

GREER, S. L. The politics of divergent policy. In GREER, S.L. (Ed.). Territory, democracy and justice: Regionalism and federalism in Western Democracies. New York: Palgrave MacMillan, 2006. p. 157-174.

HUMPREYS, M.; SACHS, J. D.; STIGLITZ, J. E. What is the Problem with Natural Resouce Wealth? In: HUMPREYS, M.; SACHS, J. D.; STIGLITZ, J. E (Eds.). Escaping the Resource Curse. New York: Columbia University Press, 2007. p. 1-20.

LECOURS, A.; BÉLAND, D. The Institutional politics of territorial redistribution: Federalism and equalization policy in Australia and Canada. Canadian Journal of Political Science, v. 46, n. 1, p. 93-113, 2013. 
OBINGER, H.; LEIBFRIED, S.; CASTLES, F. G. (Eds.). Federalism and the welfare state: New world and European experiences. New York: Cambridge University, 2005.

PALERMO, V. Como se governa o Brasil? O debate sobre instituições políticas e gestão de governo. Dados - Revista de Ciências Sociais, v. 43, n. 3, p. 521-557, 2000.

PALERMO, V. Brazilian Political Institutions: an Inconclusive Debate. Brazilian Political Science Review, v. 10, n. 2, e0003, 2016.

RIKER, W. H. Federalism: Origin, Operation, Significance. Los Angeles: Little Brown, 1964.

PIERSON, P. Politics in time: History, institutions, and social analysis. New Jersey: Princeton University, 2004.

SCHARPF, F. W. The join-decision trap: Lessons from German federalism and European integration. In: KINCAID, J. (Ed.). Federalism. London: SAGE Publications, 2011. p. 333-376.

SEGATTO, C. I.; ABRUCIO, F. L. Os múltiplos papéis dos governos estaduais na política educacional brasileira: os casos do Ceará, Mato Grosso do Sul, São Paulo e Pará. Revista de Administração Pública, v. 52, n. 6, p. 1179-1193, 2018.
SIMEON, R. Federalism and social justice: thinking through the tangle. In: GREER, S. L. (Ed.). Territory, democracy and justice: Regionalism and federalism in Western democracies. New York: Palgrave MacMillan, 2006. p. 18-43.

SINGER, A. Brasil, junho de 2013: classes e ideologias cruzadas. Novos Estudos CEBRAP, v. 97, p. 23-40, 2013.

STEPAN, A. Para uma nova análise comparativa do federalismo e da democracia: Federações que restringem ou ampliam o poder do demos. Dados, v. 42, n. 2, p. 197-251, 1999.

TROJBICZ, B. Federalism and Governability in Brazil: Oil Royalties in Dispute. Bulletin of Latin American Research, v. 38, n. 5, p. $607-$ 623, 2019.

TROJBICZ, B. Política pública de petróleo no Brasil: da liberalização ao Pré-Sal. Rio de Janeiro: Elsevier, 2016.

WATTS, R. L. Origins of cooperative and competitive federalism. In: GREER, S. L. (Ed.). Territory, democracy and justice: Regionalism and federalism in Western democracies. New York: Palgrave MacMillan, 2006. p. 201-223.

Beni Trojbicz

ORCID: https://orcid.org/ 0000-0002-0537-8147

Doutor em Administração Pública e Governo; Professor Adjunto da Faculdade Interdisciplinar de Letras da Universidade Federal dos Vales do Jequitinhonha e Mucuri (UFVJM), Minas Gerais - MG, Brasil. E-mail: btrojbicz@gmail.com 


\section{ANEXO}

\section{Entrevistas}

Abraham Lincoln Ferreira Cardoso. Assessor de Minas e Energia para a Liderança Partidária do Movimento Democrático Brasileiro (MDB) na Câmara dos Deputados. Brasília, DF, 07 jul. 2014.

Alceu Moreira. Deputado Federal. Porto Alegre, 20 out. 2014.

Carlos Zarattini. Deputado Federal. São Paulo, 14 nov. 2014.

Eduardo Stranz. Assessor da Presidência da Confederação Nacional de Municípios. Porto Alegre, 20 jan. 2015.

Humberto Souto. Deputado Federal. Belo Horizonte, 11 fev. 2015.

Ibsen Pinheiro. Deputado Federal. Porto Alegre, 03 jun. 2014.

Entrevistado No. 1. Assessor Legislativo da Câmara dos Deputados para Minas e Energia. Brasília, DF, 14 maio 2014.

Entrevistado No. 2. Assessor legislativo da Câmara dos Deputados para Minas e Energia. Brasília, DF, 06 maio 2014.

Entrevistado No. 3. Assessor Legislativo do Senado Federal. Brasília, DF, 29 abr. 2014.

Jerônimo Cabral Guedes. Assessor de Minas e Energia para a Liderança Partidária do Partido dos Trabalhadores (PT) na Câmara dos Deputados. Brasília, DF, 10 fev. 2015.

Leonardo Carneiro Monteiro Picciani. Deputado Federal. Brasília, DF, 16 dez. 2014.

Marcos Antonio Félix Figueiredo. Assessor de Minas e Energia para a Liderança Partidária do Partido da Social Democracia Brasileira (PSDB) na Câmara dos Deputados. Brasília, DF, 14 ago. 2014.

Paulo Teixeira. Deputado Federal. Brasília, DF, 27 jan. 2015. 